\title{
Smokers, virgins, equity and health care costs
}

\author{
Hugh V McLachlan Glasgow Caledonian University, Glasgow
}

\begin{abstract}
Fulian Le Grand's case for saying that it would be equitable if smokers and smokers alone were to pay the costs of smoking-related health care is considered and found to be deficient.
\end{abstract}

Should smokers (and smokers alone) pay the costs of smoking-related health care? No - I shall suggest - at least in contemporary Britain, they should not. I will consider the question with specific reference to the philosophy of public health finance of Le Grand. This philosophy of Le Grand's is based upon a very dubious notion of 'equity'. Nonetheless, what he says about smoking and health care costs is of interest in its own right and might well be attractive to some people who have no knowledge of nor interest in his views about 'equity'.

According to Le Grand: 'Situations where one person is disadvantaged relative to another due to factors beyond either's control are commonly judged inequitable; situations where the disadvantage arises because of differences in individual choices freely made are not. Equity depends on the extent of individual choice' (1). I do not think that people normally conceive of equity and inequity in this way. More importantly, they should not conceive of equity and inequity after this particular fashion. I shall use the term 'equity' in what I think is the normal usage, whereby, 'equity', 'fairness' and 'justice' are identical or, at least, very, very similar.

Due to factors beyond our control, at our births, Kenny Dalglish was and I was not a potentially great footballer yet, it would be bizarre of me to claim that regarding the distribution of football-playing talents I have been treated inequitably. Perhaps I have been unlucky but that is a different matter. Suppose that a tyrant in some society economically very much less developed than our own decided independently of the choices and wishes of the people to install, in the interest of public health, a public sewerage system. The decision and its implementation need not be

\section{Key words}

Smoking; health care costs. inequitable no matter that tyranny, as a general thing, is inequitable and no matter whether or not the undertaker is thereby disadvantaged relative to, say, the tailor, due to factors beyond the tailor's and the undertaker's control.

Suppose that, in a liberal democracy, one of the parties which has a chance of forming a government promises lower taxation and lower public expenditure than the party promises and delivers which succeeds in forming a government. Would it be inequitable if, contrary to their expressed wishes as interpretable from their voting choice, those voting for the losing party ended up paying the same amount in taxes as did those who voted for the winning party and, at least by implication, consented to the resultant level of taxation? Surely not. Otherwise liberal democracies must be - as they might be on other grounds - inherently inequitable.

I think that Le Grand's account of equity is unacceptable. I do not believe that he has articulated an applicable principle of equity. But, suppose that he had done. Let us suspend our disbelief in Le Grand's premise and see where his argument leads him.

According to Le Grand: 'If an individual's ill health results from factors beyond his or her control, then the situation is inequitable; if it results from factors within his or her control, then it is equitable' (2). Le Grand implies that people can choose to smoke or not to smoke and that those who choose to smoke know the health risks they are running. Those who do not voluntarily run the risk of suffering from smoking-related conditions, diseases and illnesses non-smokers - should not be required to pay towards the associated health care costs. Those who suffer from smoking-related conditions and illnesses should not themselves pay the full costs of consequent health care, according to Le Grand. Since not all smokers will suffer from the conditions and illnesses and there is merely a risk and not a certainty that any particular smoker will incur smokingrelated health care costs, Le Grand thinks that it follows that it is the group of risk-takers - the smokers - and not merely the cost-incurrers - the smokers who suffer from smoking-related illnesses 
and conditions - who should, between them, pay the costs of smoking-related health care.

Le Grand argues that health care costs should be met in two sorts of ways, corresponding to his distinction between costs which are the result of risks voluntarily run and other health care costs.

$\mathrm{He}$ says that, where people suffer ill health as a result of factors beyond their control '... they should not suffer losses in consequence; hence, they should have treatment free at the point of use and financed by the community' (3). He claims that: 'In cases where health risks are not obviously identifiable, then everyone is in some sense at equal risk and, therefore, everyone should bear the expected value of the relevant losses' (4). A uniform tax should, he suggests, finance this sort of expenditure.

\section{Special task}

On the other hand, he says that: 'In addition, if it were established that some activities (such as smoking), did create greater health risks than others, then a special tax should be levied on those activities, at a level sufficient to generate enough revenue to finance the extra treatment costs. Again the special tax would be hypothecated ...' (5).

This is in line with Le Grand's related assertions: first of all that, where activities are voluntarily embraced and have known health risks, everyone who indulges in the activity should bear the associated health care costs whether or not the indulging is injurious to his or her own health and secondly that only those who voluntarily indulge should bear such costs.

Notice here that the element of compulsory taxation, taxation that is involuntary, beyond the control and choice of individual taxpayers raises a question about the internal consistency of Le Grand's rationale for his proposed health system. If Le Grand were to be proposing rules for the constitution of a club or some such thing that people could freely choose to join or not to join then the matter would be different; but Le Grand is talking about a non-optional taxation scheme of a (non-optional, in effect) state. To say the least, it is curious to advocate compulsory taxation in order to further equity as defined by Le Grand. It is particularly curious and, on the face of it, particularly paternalistic to force people not to take a risk which they might well have chosen to take, namely the risk of becoming unwell and not receiving all the treatment which might, to good effect, have been directed towards the restoration of their health.

Compulsory taxation, I have no doubt, often is justifiable but it is justifiable on grounds other than what Le Grand thinks of as 'equity' and it is justifiable as compulsory taxation rather than as an enforced pre-payment for some particular good or service. To what should people be entitled solely as a consequence of having paid in taxation what it was their due to pay? They should be entitled not to go to jail for tax evasion.

I might here inadvertently have given the impression that I think that indirect taxation such as, say, taxation on tobacco should, somehow, be thought of $\Rightarrow$. as voluntary taxation on the grounds that smoking is a voluntary activity. I do not take this view at all. Very few people, I would suppose, choose to smoke $\frac{\bar{\sigma}}{\bar{n}}$. and also to pay tobacco duty. Most people who? choose to smoke would rather not pay the tobaccoळ duty and pay it because they are coerced into doing so. Those who would choose to pay the tax (if there $\overrightarrow{0}$ were any) are also forced to pay it independently of their wills. Choice and control are separate matters. $\vec{\omega}$ Suppose that there were to be a tax imposed on, say, voting for the Conservative Party or being a woman and that someone tried to justify this tax on thei grounds that it was a voluntary tax since people $\overrightarrow{+}_{+}^{-}$ could choose not to vote for the Conservative Partyi and, since sex change operations are available, $\subset$ people could choose not to remain female. Advocacy? of the tax on these grounds might properly be calledhypocritical and so too might a similar advocacy of taxation on smoking. I think that Le Grand'so proposed specific taxation no less than his proposed $\stackrel{\text { क }}{+}$ general taxation would conflict with his own defence $\vec{\oplus}$ of what he considers to be 'equity'.

Suppose that Nicki is a heavy smoker and a virgia. Suppose that Vicki is a non-smoker and what you might call a heavy non-virgin. According to Grand, or, rather, according to my interpretation of his argument, it would be inequitable if Vicki were $\frac{0}{\varnothing}$ required to pay any of the smoking-related health care costs incurred by Nicki (or any other smokers)을 on the grounds that (equity requires that) smokers and smokers only - as a group should pay the costs of health care which is directed towards the treatment of conditions the risk of whose acquisition knowably is increased by smoking. Whether or not ${ }^{\Phi}$ Le Grand's grounds are the grounds of equity - I do 3 . not think that he is citing the principle of equity but suppose that he were - it would be inequitable, in the usual sense of the term (as well as in Le Grand'so sense) to acquit Vicki of an obligation to pay towards the smoking-related health care costs of Nicki ando other smokers and still to insist that Nicki helped to pay for the sex-related health care costs of Vicki and $O$ other non-virgins.

\section{Health care surcharge}

If equity required that Nicki paid a health care sur-? charge for being a smoker then it would equally, so it $\stackrel{\oplus}{\rightarrow}$ seems to me, require that she received a correspond- 0 ing rebate for being a virgin. Perhaps you can ando우 should run a private club or a private insurance scheme along principles such as this but, I would $\overrightarrow{\mathbb{Q}}$ suggest, you cannot and should not try so to organise $\frac{a}{\sigma}$ a society nor a public health system. If you do try to organise a society or public health system on the basis 
of such a principle then you ought at least to apply the principle consistently and generally. To pick on merely, say, smokers would be unjust, unfair and inequitable.

Smokers and virgins are people and ought to be treated as individual people rather than merely as members of particular groups. If people who are smokers are treated as smokers rather than as individual people, then they should also simultaneously be treated as members or non-members of all the other health-risk categories which there are otherwise they will be treated arbitrarily and, in the usual sense of the term, inequitably. A system where, arbitrarily, one group of people is given no support in meeting the costs of the health care which their risk has brought about and is simultaneously forced to help to meet the health care costs which are brought about by the voluntary and knowably risky behaviour of other people seems to me to be manifestly unjust (whatever other merits it might have). Hence, if you want to discriminate against smokers with regard to health care costs and you want to discriminate on the grounds of equity, then make sure that you also discriminate against non-virgins and all other risk-taking and risk-creating groups. Le Grand explicitly states that we should discriminate against all such groups but, given that there are so many of them to choose from, it is perturbing that he refers so often to smokers. What about, say, motorists, drinkers, carnivores and those who take insufficient exercise?

\section{'Passive worrying'}

Le Grand's proposal is a dangerous one because, while it is clear that the partial and arbitrary application of his principle will be unfair, unjust and inequitable, it is equally clear that the impartial and consistent application of his principle would not be, for various economic and political reasons, a feasible proposition. For instance, while smoking can be readily monitored, quantified and taxed, other relevant activities (and the lack of them) cannot. Think, say, about the failure to take adequate exercise. Think about worry - a dreadfully unhealthy activity. Think about sex! In addition, while there seems to be votes in the distasteful practice of baiting smokers, there would presumably be none in trying to penalise financially, say, non-virgins and worriers. Through the company of over-anxious, stressed and stressful friends and colleagues, how many of us are the victims of 'passive worrying'? Worrying - so my own experiences of relaxation therapy and of nicotine addiction suggest - is, with proper instruction (which is available within the NHS) no more difficult to give up than smoking is. Or, it can be.

Suppose it were to be announced that, as from, say, next week, the health care costs relating to activity $\mathrm{Q}$ - and the health care costs relating only to $Q$ : the health care costs relating to activities $R, S, T$,
$\mathrm{U}$... $\mathrm{Z}$ will be financed from general taxation - will be borne solely by those who indulge in $Q$. Depending upon what activity $Q$ were - playing tennis?; hill-walking? - there might be a public outcry. Whatever $\mathrm{X}$ were, including smoking or having sex, there ought to be, I am suggesting, an outcry on the basis of fairness, justice and equity. If there were no National Health Service; if there were no compulsory financing of the health care of others; if all health care payments were voluntary then the situation might be quite different.

Suppose that Nicki, the smoker and virgin, will develop and die from lung cancer. Suppose that this will occur under a Le Grand-inspired regime. Given that the cost of Nicki's smoking-related health care will have been pre-paid compulsorily by Nicki and her fellow-smokers then, unlike under the National Health Systems as it currently prevails, Nicki will have a moral right and should have a legal right to the treatment she needs. Non-smokers, please be prepared to stand aside for her! What if she decides to forego medical treatment or to forego all but the most rudimentary sort of it? In these circumstances, since her treatment would have been previously paid for, I think that she would have a case for demanding a cash rebate in lieu of the requisite treatment. Otherwise, would she not be treated (in a different sense of the term) unjustly, unfairly? Would she not be being ripped off by the Le Grand system of 'equitable' health care?

Similarly, given her smoking-related illness, there are costs, including health care costs which she will be unable to impose or, at least, be far less likely to impose on the community than she would have been able to had she not smoked. For instance, Nicki, let us assume, will not receive an old age pension; she will not suffer from nor require, at great cost, to be treated for senile dementia; she will receive no sports injuries nor consequent treatment for them; she will spare her GP a huge catalogue of consultations as the result of her early death. If Nicki is going to be financially penalised for the costs attendant upon her being a smoker, it would be unfair were she not to receive a rebate, under a Le Grandian system, for the costs which will have been saved as a result of her smoking. If it were to turn out that, overall, smoking and smokers were not a drain on public expenditure but the opposite, would consistent adherence to Le Grand's principles lead one to advocate the public subsidisation of smoking and smokers?

\section{Moral duty}

The picture that emerges of a Le Grand-inspired health care system is an interesting although a very curious one. Curious too would be the sort of society of which a Le Grandian health care and healtr. care costs system could form a characteristic part. Indeed, it hardly seems at all like a society of citizens and taxpayers: it seems more like a club or some 
quasi-voluntary association with a collection of highly self-regarding members. In a normal society, citizens pay taxes as a legal and, in general, a moral duty to support public expenditure in general, where there will only be by accident (if at all) any correspondence or proportion between what an individual taxpayer contributes and what (if anything) he or she receives individually in return. Under Le Grand's scheme, what smokers, for instance, specifically contribute towards the financing of state expenditure sounds more like enforced pre-payment for a specified service rather than normal taxation. With normal taxation, we all p... in the same pot and its contents are distributed without regard to characteristics of the contributors qua contributors or the extent of their individual contributions. Does Le Grand think that all public finance and expenditure should take the form which he suggests in relation to health care? If not why not? If one's contribution to the financing of health care costs should vary in relation to one's likely enjoyment of the services provided, then why should not one's contribution to the financing of all state expenditure so vary? (Conversely, if one's contribution to state spending in general should not be based on one's enjoyment of the consumption of the goods and services involved, why should it be in the case of health care costs?) Some people want, for instance, more money spent than others do on defence. Should those of us who think that defence spending is too high receive a tax rebate? Some people benefit more than others from state expenditure on education. Should there be a relationship between the benefits that individual people receive from education and what individual people pay in taxation towards education? Would there be such a relationship in a consistently ordered society in which a Le Grand-inspired health care costs system was at home? I hope that I am able to control my own life and exercise my own choice (or to be sufficiently lucky) such that I do not end up living in such a society.

\section{Motor-cyclists}

Le Grand asks the questions: 'Do heavy smokers who contract lung cancer have the same claim, on equity grounds, to resources to restore them to full health (so far as that might be possible) as nonsmokers who contract the disease? Are drivers who refuse to put on seat-belts, or motor-cyclists who refuse to wear helmets, entitled to as much compensation in the event of an accident as those who do not take those precautions? More generally, should not those who consciously and voluntarily assume health risks in order to undertake some activity solely of benefit to themselves bear the consequences if these prove adverse' (6)?

Here, several questions - for rhetorical effect? are run together which would be better separated. The correct answers to them are, I think: yes, smokers do have the same claim; no, such drivers and motor-cyclists should not be entitled to as $\cong$ much compensation (apart from anything else it is not and it should not be illegal to smoke: it is illegal to drive without a seat belt and to ride a motor-cycle $\Rightarrow$ minus a helmet) and no, such people should not in $\stackrel{5}{\rightarrow}$ particular pay or pay towards their own healtho costs at least not in Britain while the NHS still흐 persists.

Notice that while the heavy smoker and the non- $\frac{\vec{\Phi}}{2}$ smoker will, I suggest, ceteris paribus have a claim to medical treatment, neither has a right to receive the ${ }_{-}$ required treatment in the sense that someone or. somebody carries a duty to provide it. Perhaps both $\vec{\omega}$

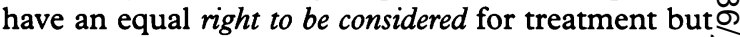
the outcome of the consideration might, in some cases, be the reasonable judgment that treatment ${ }_{i}^{\infty}$ should be withheld. For instance, perhaps both people are so ill that the treatment required would be $\stackrel{+}{+}$ inordinately expensive and would have very little 8 chance of success. On some occasions a choiceo might have been made between providing treatment to a non-smoker whose lungs are so badly damaged $\triangleright$ - whether through his own voluntary and informedco actions or not is beside the point - that the chances क of successful treatment are slight and providing the $\vec{\overrightarrow{ }}$ treatment to a heavy smoker whose chances of 8 benefiting from the treatment are extremely goof. The situation here should not be regarded as beirg akin to that of a school headmaster or headmistress distributing punishment or praise nor to a court - to refer to Le Grand's curious, in the circumstances, $\frac{\mathscr{Q}}{\varnothing}$ question about the motorist and motor-cyclist - dis- $\varrho$ tributing compensation. The smoker here might $\overrightarrow{\overrightarrow{0}}$ have a stronger claim than the non-smoker to receive 3 the treatment.

The claim that smokers as a group should pay the costs of smoking-related health care is provocative but unconvincing. Should the costs of treating $\Phi$ smoking-related illnesses and conditions be paid $\frac{5}{3}$ solely by smokers while the costs of treating $X-$. related illnesses and conditions, Y-related illnesses $ᄋ$ and conditions and Z-related illnesses and condi-

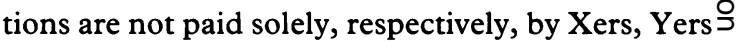
and Zers but are paid involuntarily by all people $\frac{}{0}$ including smokers? At least on the grounds of equity, fairness and justice, one would have to say: N no, definitely not. To be fair to Le Grand, it must $N$ be stressed that he does not say that it is only smokers as a group who, as a group, should pay for ${ }^{\omega}$ the treatment of the illnesses and conditions which they knowingly run the risk of suffering from: other groups, he says, should be similarly required to do so. Nonetheless, we know that it is not feasible that all risk-taking groups ever would ${ }_{0}^{0}$ be faced with this requirement. We can say with $\overrightarrow{\mathbb{D}}$ justified confidence that, in Britain at least, there $\frac{\stackrel{?}{P}}{\mathbb{P}}$ will not be in the imaginable future a tax on, say, 음 sexual intercourse nor on failure to take sufficient exercise. 


\section{A very curious society}

Even if, somehow, Le Grand's principle of the payment of health-care costs could be applied consistently and equitably, he gives no convincing argument to suggest that it should be. The sort of society where it were consistently applied would seem to be - insofar as one can imagine it - a very curious one. What other curious features would the society need to possess in order to allow for the consistent applications of Le Grand's principle? Should the health care costs pertaining to all particular thereby by addition to all - knowably avoidable illness and conditions be paid solely by those who run the risk of suffering from particular knowably avoidable illnesses and conditions? No, I do not think so. More attractive or, at least, less unattractive would be the principle that: the health care costs pertaining to all knowably avoidable illnesses and conditions (just like the rest of them) should be paid by those who voluntarily run the risk of suffering from any knowably avoidable illness or conditions which would seem to be any of us who live and breathe ... or ride in motor cars and/or are pedestrians ... or eat ... or have sex ....

Hugh $V$ McLachlan, $M A, P h D$, is Lecturer in Sociology, Department of Social Sciences, Glasgow Caledonian University, Glasgow.

\section{References}

(1) Grand J. Equity and choice: an essay in economics and applied philosophy. London: Harper Collins Academic, 1991: 176.

(2) See reference (1): 114

(3) See reference (1): 124

(4) See reference (1): 125.

(5) See reference (1): 123.

(6) See reference (1): 113-114.

\section{News and notes}

\section{Emerging zoonoses}

The 1st International Conference on Emerging Zoonoses will be held from November 24-28, 1996 in Jerusalem, Israel. The language of the conference will be English.

The conference will cover: cryptosporidiosis, toxoplasmosis, microsporidiosis, toxocariasis, cat scratch disease, lyme disease, ehrlichiosis, brucellosis, rabies, pulmonary hanta syndrome, haemorrhagic fevers, borna disease, rickettsia, laboratory diagnosis, drug development etc.

For further information please contact: Marilyne Katz, Secretariat on behalf of the Organizing Committee, PO Box 29041, Tel Aviv 61290, Israel, Tel: +972 3 5175149/50, Fax: +97235175155. 